\title{
EDITORIAL
}

\section{New cover and website mark the 25th anniversary of Powder Diffraction}

This year is the 25th anniversary of Powder Diffraction. To mark this special occasion, our graphic designer, Carly Bray, has designed a new cover that vividly displays what the content of the journal is about. Many thanks go to Carly for her beautiful work. Also this year is a new website: http:// powderdiffractionjournal.com. This reconfiguration, completed and housed by the American Institute of Physics, is on their $\mathrm{C} 3$ platform. On the new platform you can easily search volume and page number, keyword, or digital object identifier number with the new search tab. You can also perform an advanced search, updated from the previous platform to be more user-friendly. Browsing the journal is much easier and the pages look more modernized. If you are interested in keeping up with our technical reports, editorials, or other types of articles, you can do so with an RSS feed. Within the HTML display of an article you can "mark" or select an area of text and find other places within the journal on the same topic. Also very helpful, you are now able to view your recent browsing history, allowing you to see the list of articles you have been looking at as you browse the journal. We at Powder Diffraction hope you will peruse the website and enjoy its new features.

Nicole M. Ernst Boris Managing Editor 